\title{
Impact of Severity of Coronary Artery Stenosis and the Collateral Circulation on the Functional Outcome of Dyssynergic Myocardium After Revascularization in Patients With Healed Myocardial Infarction and Chronic Left Ventricular Dysfunction
}

\author{
Abdou Elhendy, MD, PhD, Jan H. Cornel, MD, Jos R.T.C. Roelandt, MD, PhD, \\ Peter R. Nierop, MD, Ron T. van Domburg, MSc, Marcel L. Geleijnse, MD, \\ Giuseppe Trocino, MD, Jeroen J. Bax, MD, PhD, M. Mohsen Ibrahim, MD, \\ and Paolo M. Fioretti, MD, PhD
}

The aim of this study was to assess the influence of the severity of coronary artery stenosis and the grade of collateral circulation on myocardial viability in patients with chronic left ventricular (LV) dysfunction undergoing coronary artery bypass grafting. Forty patients lage 59 \pm 8 years) with old myocardial infarction were studied by dobutamine stress echocardiography (DSE) before coronary artery bypass grafting. LV function was assessed using a 16-segment, 5-grade score model. Viability and functional recovery were respectively defined as a reduction in wall motion score $\geq 1$ at low-dose DSE and at follow-up echocardiograms obtained 3 months after surgery. There were 56 stenotic coronary arteries subtending severely dyssynergic myocardial segments, of which 38 were occluded. Among 186 severely dyssynergic segments, functional recovery occurred in $\mathbf{4 2}$ (23\%). There was no significant difference between myocardial regions with patent or occluded coronary arteries with respect to prevalence of viability or functional

- revious studies have demonstrated the value of coronary artery bypass grafting in amelioration of symptoms, improvement of left ventricular (LV) function and prolongation of survival in patients with chronic ischemic LV dysfunction. ${ }^{1,2}$ The assessment of myocardial viability is important to predict the occurrence of functional improvement of dyssynergic myocardium after revascularization., ${ }^{3,4}$ The utility of various techniques in this setting has been established. These include positron emission tomography, thallium-201 scintigraphy, and low-dose dobutamine echocardiography. ${ }^{2-4}$ Few studies have as-

From the Thoraxcenter, University Hospital Rotterdam-Dijkzigt, Eras mus University, Rotterdam, The Netherlands. This study was supported in part by the Department of Cardiology, Cairo University Hospital Cairo, Egypt and Grant NHS 94.135 from the Dutch Heart Foundation, Den Haag, The Netherlands. Manuscript received July 8 , 1996; revised manuscript received and accepted November 8 , 1996 .

Address for reprints: Abdou Elhendy, MD, PhD, Thoraxcenter, Ba 300, Dr Molewaterplein 40, 3015 GD Rotterdam, The Netherlands. recovery and percentage of viable or recovered segments relative to the total number of dyssynergic segments. In patients with total occlusion, these parameters were not different between regions with different collateral grades. Sensitivity, specificity, and accuracy of low-dose DSE for prediction of regional functional recovery were $71 \%, 90 \%$, and $86 \%$, respectively. It is concluded that in patients with chronic LV dysfunction, the presence of total occlusion of coronary arteries supplying severely dyssynergic regions does not imply a lower prevalence or extent of functional recovery after revascularization, regardless of the grade of angiographically visualized collaterals. Low-dose DSE can identify myocardial regions with a high probability of functional improvement after revascularization regardless of the severity of underlying coronary stenosis or collateralization of the involved coronary vessel. (C) 1997 by Excerpta Medica, Inc.

(Am J Cardiol 1997;79:883-888)

sessed the relation between coronary angiographic findings and metabolic markers of myocardial viability in patients with chronic LV dysfunction. ${ }^{5,6}$ However, angiographic findings in these studies were not correlated with the functional outcome after revascularization. Therefore, the aim of this study was to assess the relation between the severity of coronary artery stenosis in patients with chronic LV dysfunction and myocardial viability at low-dose dobutamine echocardiography and to determine the impact of the severity of coronary stenosis and collateral circulation to occluded coronary arteries on the prevalence and magnitude of functional improvement of dyssynergic segments after revascularization.

\section{METHODS}

Study patients: The study population was derived from a consecutive series of patients with LV dysfunction who underwent dobutamine stress echocardiography (DSE) for the diagnosis of myocardial 
ischemia and viability before coronary artery bypass grafting. Patients were included if they fulfilled the following criteria: (1) the presence of proximal or mid-coronary artery stenosis ( $\geq 50 \%$ luminal diameter stenosis) of $\geq 1$ major coronary artery subtending a severely dyssynergic myocardial region (akinesia or severe hypokinesia); (2) coronary artery bypass grafting of arteries supplying the dyssynergic regions performed within 1 month after DSE without concomitant myocardial resection; and (3) absence of perioperative infarction. Forty patients fulfilled these criteria (30 men and 10 women, age $59 \pm 8$ years) and gave an informed consent to undergo DSE before and after surgery. Symptoms before surgery included angina in 37 patients and dyspnea in 8 patients. Beta-blocking agents were stopped 2 days before DSE. Medications on the day of the test included calcium channel blockers in 20 patients, nitrates in 29 patients, and angiotensin-converting enzyme inhibitors in 24 patients. All patients had a previous myocardial infarction by the standard criteria of chest pain, diagnostic increase in cardiac enzymes, and serial electrocardiographic changes. The mean time from infarction was $4 \pm 5.3$ years (range 6 months to 25 years). The infarction was anterior (or anterolateral) in 19 patients, inferior (or inferoposterolateral) in 12 patients, and in both locations in 9 patients.

Dobutamine stress test: Dobutamine stress testing was performed as previously described. ${ }^{4}$ Dobutamine was infused through an antecubital vein starting at a dose of $5 \mu \mathrm{g} / \mathrm{kg} / \mathrm{min}$ followed by $10 \mu \mathrm{g} / \mathrm{kg} /$ min (3-minute stages), increasing by $10 \mu \mathrm{g} / \mathrm{kg} / \mathrm{min}$ every 3 minutes to a maximum of $40 \mu \mathrm{g} / \mathrm{kg} / \mathrm{min}$. Atropine (up to $1 \mathrm{mg}$ ) was given to patients not achieving $85 \%$ of their age-predicted maximal heart rate at the maximal dobutamine dose.

Stress echocardiography: Echocardiographic images were acquired in the standard views as previously described. ${ }^{4}$ The echocardiograms were digitized on optical disk and displayed side by side in quad-screen format (Vingmed-CFM 800, Vingmed Sound A/S, Horten, Norway) to facilitate the comparison of rest, low-dose, and maximal stress images. The LV wall was divided into 16 segments and scored using a 5-point scale, where $1=$ normal, $2=$ mild hypokinesia, $3=$ severe hypokinesia, $4=$ akinesia, $5=$ dyskinesia. ${ }^{4}$ Severe dyssynergy was defined as akinesia or severe hypokinesia. The interpretation of images was performed by 2 independent observers without the knowledge of the patients' angiographic data. In case of disagreement, a majority decision was achieved by a third reviewer. In our laboratory, inter- and intraobserver agreement for stress echocardiographic assessment are $92 \%$ and $94 \%$, respectively. ${ }^{7}$ Both wall motion and thickening were considered for analysis. The diagnosis of ischemia was based on the occurrence of new or worsening wall motion abnormalities. Ischemia was not considered when akinetic segments at rest became dyskinetic without improvement at low-dose dobutamine. ${ }^{8,9}$ Myocardial viability in severely dyssynergic segments was defined as $\geq 1$ decrease in wall motion score during low-dose dobutamine (5 to $10 \mu \mathrm{g} / \mathrm{kg} / \mathrm{min}$ ).

Follow-up studies: A rest echocardiogram was performed in all patients 3 months after surgery. Functional recovery of severely dyssynergic segments was defined as a reduction in wall motion score $\geq 1$. On the day of performing the follow-up echocardiograms, DSE was repeated in 28 patients. The remaining 12 patients did not wish to repeat the test.

Coronary angiography: Coronary angiography was performed using the Judkins technique within 1 month of DSE in all patients. Coronary stenosis was quantified using a previously described method from our center. ${ }^{10}$ Significant coronary artery disease was defined as a diameter stenosis $\geq 50 \%$. Collateral channels to completely occluded coronary arteries were assessed by observing the degree of opacification distal to the occlusion and was graded using the Thrombolysis in Myocardial Infarction (TIMI) trial classification ${ }^{5,11}$ : grade 1 , absent filling to the distal vessel; grade 2, minimal, in case of faint opacification of the distal vessel or visualisation of a small vessel; and grade 3, well-developed collaterals with visualization and dense opacification of the entire distal vessel. Coronary arteries were assigned to particular echocardiographic myocardial segments as previously described. ${ }^{12}$ Two experienced observers who were unaware of the results of the dobutamine stress test reviewed the angiograms. In case of disagreement, a consensus was reached by a third observer. For stenotic coronary arteries subtending severely dyssynergic regions, the following regional echocardiographic parameters were studied in the corresponding area: wall motion score index (derived by the summation of the score of individual segments in a vascular region divided by the total number of segments in that region), prevalence of ischemia, prevalence of viability in severely dyssynergic segments at low dose dobutamine, viability index (derived by dividing the number of severely dyssynergic segments that improved at low-dose DSE by the number of severely dyssynergic segments in the same region), and prevalence of functional recovery of severely dyssynergic segments after surgery and recovery index (derived by dividing the number of severely dyssynergic segments with functional recovery by the number of severely dyssynergic segments in the same region).

Statistical analysis: Unless specified, data are presented as mean $\pm \mathrm{SD}$. The chi-square test was used to compare differences between proportions. Analysis of variance was used to determine the differences between groups. The Student's $t$ test was used for analysis of continuous data. A p value $<0.05$ was considered significant. Sensitivity, specificity, predictive value, and accuracy were derived according to standard definitions and presented with their corresponding $95 \%$ confidence intervals.

\section{RESULTS}

Coronary angiography: There were 56 arteries supplying severely dyssynergic myocardial regions. The 


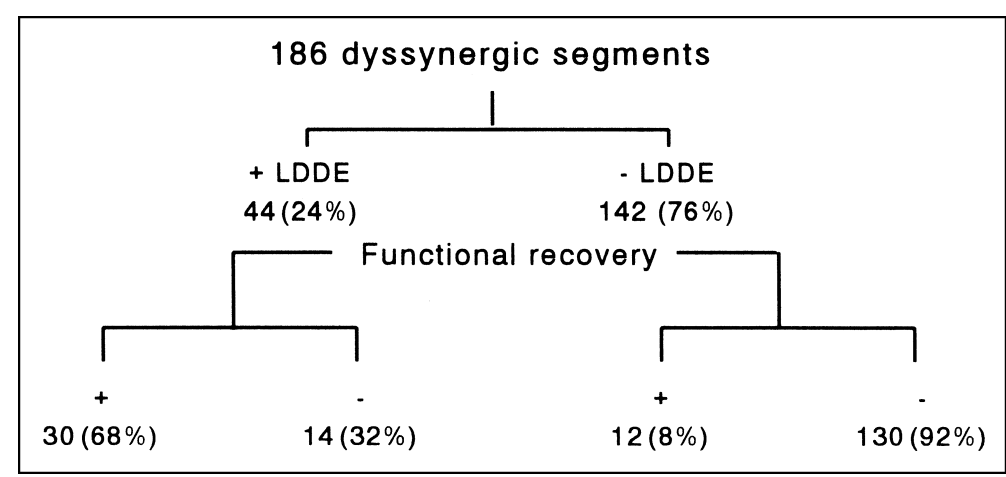

FIGURE 1. Flow chart with the results of low-dose dobutamine echocardiography (LDDE) for the detection of myocardial viability in severely dyssynergic segments and the prediction of functional recovery after revascularization.

TABLE I Diagnostic Accuracy of Low-Dose Dobutamine Echocardiography for the Prediction of Functional Recovery of Severely Dyssynergic Segments After Coronary Artery Bypass Grafting

\begin{tabular}{|c|c|c|c|c|}
\hline SENS $(95 \% \mathrm{Cl})$ & SPEC (95\% Cl) & PPV $(95 \% \mathrm{Cl})$ & NPV (95\% Cl) & $\operatorname{ACC}(95 \% \mathrm{Cl})$ \\
\hline $71 \%(65-78)$ & $90 \%(86-95)$ & $68 \%(61-75)$ & $92 \%(88-96)$ & $86 \%(81-91)$ \\
\hline
\end{tabular}

involved arteries were: the left anterior descending (28 territories), left circumflex (11 territories), and the right coronary artery (17 territories). Of these arteries, $38(68 \%)$ were occluded. Coronary collaterals observed were: grade 1 in 7 arteries $(18 \%)$, grade 2 in 10 arteries (26\%), and grade 3 in 21 arteries $(55 \%)$. Eighteen arteries were patent with a diameter stenosis $\geq 50 \%$ (mean $65 \pm 8 \%$ ). Of the 40 patients, 7 had 1-vessel disease (18\%), 13 had 2vessel disease (33\%), and 20 (50\%) had 3-vessel disease. The angiographic ejection fraction in the whole population was $41 \pm 13 \%$.

Hemodynamics, clinical, and electrocardiographic data: The heart rate increased significantly from rest to peak stress $(72 \pm 13$ vs $141 \pm 15$ beats $/ \mathrm{min}$, p $<0.0001)$, whereas systolic blood pressure did not change significantly (126 \pm 23 vs $122 \pm 25 \mathrm{~mm} \mathrm{Hg}$ ). Angina occurred in 28 patients $(70 \%)$ and ST-segment depression in $15(38 \%)$.

Dobutamine stress echocardiography: At baseline, a total of 186 severely dyssynergic segments were detected in the 56 coronary artery regions. The mean number of these segments per vascular region was $3.3 \pm 2.3$ (range 2 to 9 segments). Viability at lowdose DSE was detected in 25 of the 134 akinetic segments (19\%) and in 19 of the 52 severely hypokinetic segments $(37 \%, \mathrm{p}=0.01)$. This viability pattern was observed in 21 of the 56 vascular territories (38\%) in 17 of 40 patients (43\%). In the entire population, wall motion score index decreased significantly from rest to low-dose DSE $(1.96 \pm 0.37$ vs $1.7 \pm 0.35, \mathrm{p}<0.001)$, and increased significantly at high-dose DSE $(2.24 \pm 0.37, \mathrm{p}<0.0001$ vs resting value). Ischemia was detected in 27 of the 56 vascular territories $(48 \%)$.
Follow-up data: Symptoms of angina improved in all patients after revascularization. Recovery of function occurred in 42 of the 186 severely dyssynergic segments $(23 \%)$. This was more frequent in severely hypokinetic than akinetic segments: 18 of 52 $(35 \%)$ versus 24 of $134(18 \%), \mathrm{p}=$ 0.01 . Among the 18 severely hypokinetic segments with functional recovery, 8 segments changed to normal and 10 segments changed to mild hypokinesia. Among the 24 akinetic segments with functional recovery, 6 segments changed to severe hypokinesia, 15 segments to mild hypokinesia, and 3 segments to normal.

Functional recovery occurred in 25 vascular territories $(45 \%)$ in 21 patients $(53 \%)$. The distribution of findings at low-dose DSE and functional recovery of severely dyssynergic segments after revascularization is shown in Figure 1. Sensitivity, specificity, predictive value, and accuracy of low-dose DSE in predicting postrevascularization improvement of severely dyssynergic segments are given in Table I. Functional recovery occurred in 27 of the 34 segments with a biphasic response to DSE (defined as improvement at low dose and worsening at high dose) and in 3 of the 10 segments that showed a sustained improvement at low- and high-dose dobutamine. Thus, the positive predictive value for functional recovery of a biphasic response was higher than sustained improvement ( $79 \%$ vs $30 \%, \mathrm{p}<0.005)$. In the 28 patients who underwent high-dose DSE after surgery, angina occurred only in 2 patients. Only 1 patient developed ischemia at high-dose DSE in the studied vascular territories. Among the 14 segments identified as false-positive for viability at low-dose DSE (Figure 1), 9 segments were reevaluated by DSE after surgery. Four of these segments showed a biphasic pattern before surgery that persisted after surgery in 2 and was changed to persistent improvement in 2 . The 5 other segments showed sustained improvement during DSE before and after surgery. Coronary angiography was performed in 13 patients (33\%) after surgery and revealed no significant graft stenosis in the studied regions in all patients.

Effect of coronary artery patency on myocardial viability and functional outcome: There was no significant difference (Table II) between myocardial regions subtended by occluded arteries and those with stenotic but patent coronary arteries with regard to resting, low-dose, and peak wall motions score indexes, prevalence of ischemia, myocardial viability and functional recovery, number of viable and recovered segments, and indexes of viability and functional recovery (Figure 2). No significant correlation was found between percent diameter stenosis and via- 


\begin{tabular}{|c|c|c|c|}
\hline Echocardiographic Data & $\begin{array}{c}\text { Occluded } \\
\text { Arteries } \\
(\mathrm{n}=38)\end{array}$ & $\begin{array}{l}\text { Patent } \\
\text { Arteries } \\
(n=18)\end{array}$ & $\mathrm{p}$ Value \\
\hline WMSI at rest & $2.74 \pm 0.39$ & $2.72 \pm 0.39$ & 0.9 \\
\hline WMSI at low-dose dobutamine & $2.51 \pm 0.46$ & $2.49 \pm 0.44$ & 0.8 \\
\hline WMSI at peak stress & $2.96 \pm 0.45$ & $2.89 \pm 0.43$ & 0.6 \\
\hline Number of dyssynergic segments & $3.4 \pm 2.4$ & $3.1 \pm 2.2$ & 0.9 \\
\hline Prevalence of viability & $14(37 \%)$ & $7(39 \%)$ & 0.9 \\
\hline Number of viable segments & $0.73 \pm 1.19$ & $0.87 \pm 1.42$ & 0.8 \\
\hline Viability index & $0.26 \pm 0.39$ & $0.24 \pm 0.30$ & 0.8 \\
\hline Prevalence of ischemia & $17(45 \%)$ & $10(56 \%)$ & 0.5 \\
\hline Functional recovery & $16(42 \%)$ & 9 (50\%) & 0.6 \\
\hline Number of recovered segments & $0.71 \pm 1$ & $0.78 \pm 0.9$ & 0.8 \\
\hline Recovery index & $0.24 \pm 0.35$ & $0.28 \pm 0.37$ & 0.9 \\
\hline
\end{tabular}

covery. In contrast, low-dose DSE could predict functional improvement with a moderate sensitivity and a high specificity. The biphasic response to dobutamine was more predictive of functional recovery than persistent improvement. This is consistent with our previous finding of a higher prevalence of reversible perfusion abnormalities on thallium scintigraphy in akinetic segments with a biphasic response than in akinetic segments with other patterns. ${ }^{8}$

Comparison with previous studies: Patency of the infarct-related artery and the presence of high-grade collateral circulation distal to an occluded coronary artery have been associated with more favorable

bility index $(\mathrm{r}=-0.12)$ or recovery index $(\mathrm{r}$ $=-0.18$ ). In myocardial regions subtended by occluded coronary arteries, there was no significant difference in the previously mentioned parameters between regions with different grades of collaterals (Table III).

\section{DISCUSSION}

This is the first study that evaluates the influence of patency of coronary arteries and the grade of collateral circulation on the functional outcome of dyssynergic myocardium after revascularization in patients with chronic LV dysfunction. Our results show that in these patients, the prevalence and extent of both myocardial viability assessed by low-dose DSE and functional recovery after surgical revascularization are not related to the severity of coronary stenosis or the grade of collateral circulation. These angiographic findings could not identify myocardial segments with a higher probability of functional re- changes in LV function and geometry after acute myocardial infarction..$^{113-18}$ The lack of a favorable effect of these angiographic parameters on myocardial viability in our study can be explained by the fact that our patients were studied at a mean of $4 \pm$ 5.3 years after infarction as opposed to patients with a recent myocardial infarction. In the latter group of patients, acute coronary occlusion results in evolutional changes in LV function that are dependent on myocardial flow after recanalization by thrombolysis or through collaterals to occluded arteries.11,13,15 However, in our study of patients with chronic LV dysfunction, the anatomic status of the infarct-related artery may not represent the status in the critical early phase of a myocardial infarction. Coronary artery occlusion may have developed gradually, allowing for the development of adequate collateral channels that may or may not be visualized with routine angiography. ${ }^{19,20}$ This gradual process of occlusion and collateralization may help to maintain adequate

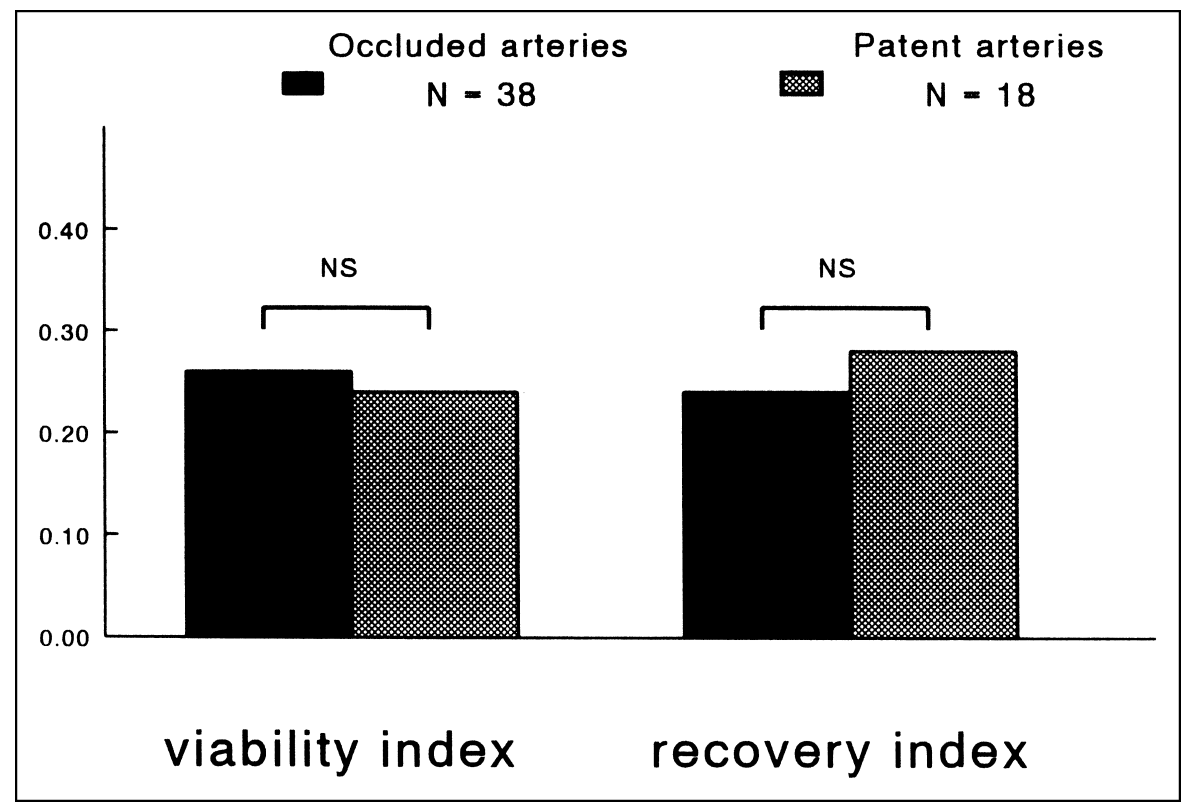

FIGURE 2. Viability and recovery indexes in myocardial regions with severe dyssynergy in presence of occlusion or patency of the related coronary artery. 


\begin{tabular}{|c|c|c|c|}
\hline Echocardiographic Data & $\begin{array}{c}\text { Grade } 1 \\
(n=7)\end{array}$ & $\begin{array}{l}\text { Grade } 2 \\
(n=10)\end{array}$ & $\begin{array}{l}\text { Grade } 3 \\
(n=21)\end{array}$ \\
\hline WMSI at rest & $2.76 \pm 0.40$ & $2.82 \pm 0.31$ & $2.66 \pm 0.42$ \\
\hline WMSI at low-dose dobutamine & $2.57 \pm 0.46$ & $2.60 \pm 0.50$ & $2.34 \pm 0.52$ \\
\hline WMSI at peak stress & $3.01 \pm 47$ & $3.07 \pm 0.49$ & $2.85 \pm 0.41$ \\
\hline Prevalence of viability & $2(29 \%)$ & $4(50 \%)$ & $8(38 \%)$ \\
\hline Number of viable segments & $0.65 \pm 1.12$ & $0.73 \pm 1.40$ & $0.75 \pm 1.61$ \\
\hline Viability index & $0.23 \pm 0.39$ & $0.26 \pm 0.37$ & $0.30 \pm 0.43$ \\
\hline Prevalence of ischemia & $3(43 \%)$ & $5(50 \%)$ & $9(43 \%)$ \\
\hline Functional recovery & $2(29 \%)$ & $4(50 \%)$ & $10(48 \%)$ \\
\hline Number of recovered segments & $0.61 \pm 1$ & $0.80 \pm 0.93$ & $0.71 \pm 1.15$ \\
\hline Recovery index & $0.20 \pm 0.35$ & $0.29 \pm 0.42$ & $0.23 \pm 0.39$ \\
\hline
\end{tabular}

blood flow to the viable myocardium. On the other hand, the presence of a patent artery may represent late recanalization of an occluded artery after the occurrence of substantial myocardial necrosis. Marzullo et $\mathrm{al}^{6}$ showed that in patients with regional LV dysfunction studied $19 \pm 34$ months after a myocardial infarction, resting coronary flow was equally reduced in the viable versus nonviable segments identified at positron emission tomography. However, coronary flow reserve after dipyridamole administration was higher in the viable segments. These data show that in patients with chronic LV dysfunction, vasodilator reserve constitutes an important factor in maintaining myocardial viability rather than resting flow, which is already reduced in both viable and nonviable regions. Finally, the selection of patients with severe regional dyssynergy in our study would result in exclusion of patients whose less severe residual coronary artery stenosis resulted in considerable myocardial salvage, and who consequently had normal or mildly impaired LV function.

Influence of collateral circulation to occluded arteries: We found that in patients with occluded coronary arteries, the grade of collaterals visualized by angiography was not related to the prevalence or extent of myocardial viability assessed by low-dose DSE. Di Carli et $\mathrm{al}^{5}$ reported similar findings in 42 patients with chronic LV dysfunction undergoing positron emission tomographic imaging. Sambuceti et $\mathrm{al}^{19}$ reported that in 19 patients with angina and isolated occlusion of the left anterior descending or left circumflex coronary artery who had not experienced a previous myocardial infarction, the angiographic score of collateral circulation was not associated with differences in myocardial function or perfusion at baseline or during pacing. This may be explained by the fact that angiography can detect epicardial collateral channels with a luminal diameter $>100$ $\mu \mathrm{m}$, whereas most of the subendocardial and intramural channels may be as small as $20 \mu \mathrm{m} .{ }^{20}$ Sabia et $\mathrm{al}^{21}$ reported that in 33 patients with recent myocardial infarctions and occluded infarct-related arteries, there was no significant correlation between the angiographic collateral grade and myocardial perfusion assessed by myocardial contrast echocardiography, inferring the importance of small collateral circuits in maintaining myocardial perfusion of viable myocardium. These nonvisualized channels may prevent permanent damage of the hibernating segments, which might improve after restoration of normal coronary flow with revascularization as demonstrated in our study. In contrast to our findings and those reported by Di Carli et al, ${ }^{5}$ Marzullo et $\mathrm{al}^{6}$ found that nonviable segments were more likely to be perfused by an occluded vessel and less collateralized than viable segments. However, the number of coronary arteries analyzed in that study was small, comprising 14 arteries of which 6 were patent.

Study limitations: Most of the analyzed myocardial regions were subtended by occluded coronary arteries $(68 \%)$. This represents the severity of coronary artery disease in a population selected for coronary artery bypass grafting. Among occluded coronary segments, only a few segments showed absent collaterals. This may be explained by chronic ischemia allowing for the development of high-grade collaterals. In the study of Di Carli et al, ${ }^{5}$ only $18 \%$ of occluded arteries subtending dyssynergic regions had absent collateral circulation. Follow-up coronary angiography was performed only in $33 \%$ of patients. However, adequacy of revascularization was demonstrated by the disappearance of ischemia and angina during DSE and symptomatic improvement after revascularization.

1. Yusuf S, Zucker D, Peduzzi P, Fisher LD, Takaro T, Kennedy JW, Davis K Killip T, Passamani E, Norris R. Effect of coronary artery bypass graft surgery on survival: overview of 10-year results from randomised trials by the Coronary Artery Bypass Graft Surgery Trialists. Lancet 1994;344:563-570.

2. Yoshida K, Gould KL. Quantitative relation of myocardial infarct size and myocardial viability by positron emission tomography to left ventricular ejection fraction and 3-year mortality with and without revascularization. J Am Coll Cardiol 1993;22:984-997.

3. Ragosta M, Beller GA, Watson DD, Kaul S, Gimple LW. Quantitative planar rest-redistribution 201-Tl imaging in detection of myocardial viability and prediction of improvement in left ventricular function after coronary bypass surgery in patients with severely depressed left ventricular function. Circulation 1993;87:1630-1641.

4. Arnese M, Cornel JH, Salustri A, Maat APWM, Elhendy A, Reijs AEM, Ten Cate FJ, Keane D, Balk AHMM, Roelandt JRTC, Fioretti PM. Prediction of improvement of regional left ventricular function after surgical revascularization: a comparison of low-dose-dobutamine echocardiography with 201-Tl single-photon emission computed tomography. Circulation 1995;91:2748-2752. 5. Di Carli M, Sherman T, Khanna S, Davidson M, Rokhsar S, Hawkins R, Phelps M, Schelbert H, Maddahi J. Myocardial viability in asynergic regions subtended by occluded coronary arteries: relation to the status of collateral flow in patients with chronic coronary artery disease. J Am Coll Cardiol 1994;23:860-868.

6. Marzullo P, Parodi O, Sambuceti G, Giorgetti A, Picano E, Gimelli A, Salvadori $\mathrm{P}, \mathrm{L}$ 'Abbate A. Residual coronary reserve identifies segmental viability in patients with wall motion abnormalities. J Am Coll Cardiol 1995;26:342350 .

7. Bellotti P, Fioretti PM, Forster T, McNeill AJ, El-Said EM, Salustri A, Roelandt JRTC. Reproducibility of the dobutamine-atropine echocardiography stress test. Echocardiography 1993;10:93-97. 
8. Elhendy A, Cornel JH, Roelandt JRTC, van Domburg RT, Nierop PR, ElSaid GM, Fioretti PM. Relation between contractile response of akinetic segments during dobutamine stress echocardiography and ischemia assessed by simultaneous 201 thallium SPECT. Am J Cardiol 1996;77:955-959.

9. Elhendy A, Cornel JH, Roelandt JRTC, van Domburg RT, Fioretti PM. Akinesis becoming dyskinesis during dobutamine stress echocardiography: A predictor of poor functional recovery after surgical revascularization. Chest 1996; $110: 155-158$.

10. Baptista J, Arnese M, Roelandt JRTC, Fioretti P, Keane D, Escaned J, Boersma E, Di Mario C, Serruys PW. Quantitative coronary angiography in the estimation of the functional significance of coronary stenosis: correlation with dobutamine-atropine stress test. J Am Coll Cardiol 1994;23:1434-1439.

11. Habib GB, Heibig J, Forman SA, Brown BG, Roberts R, Terrin ML, Boll $R$. Influence of coronary collateral vessels on myocardial infarct size in humans. Results of phase I thrombolysis in myocardial infarction trial (TIMI). The TIMI Investigators. Circulation 1991;83:739-746.

12. Marwick TH, D'Hondt AM, Baudhuin T, Willemat A, Wijns W, Detry J, Melin J. Optimal use of dobutamine stress for the detection and evaluation of coronary artery disease: combination with echocardiography, scintigraphy or both? J Am Coll Cardiol 1993;22:159-167.

13. Saito Y, Yasuno M, Ishida M, Suzuki K, Matoba Y, Emura M, Takahash M. Importance of coronary collaterals for restoration of left ventricular function after intracoronary thrombolysis. Am J Cardiol 1985;55:1259-1263.

14. Bodenheimer MM, Banka VS, Hermann GA, Trout RG, Pasdar H, Helfant
RH. The effect of severity of coronary artery obstructive disease and the coronary collateral circulation on local histopathologic and electrocardioghraphic observations in man. Am J Med 1977;63:193-199.

15. Christian TF, Schwartz RS, Gibbons RJ. Determinants of infarct size in reperfusion therapy for acute myocardial infarction. Circulation 1992;86:81-90.

16. Leung WH, Lau CP. Effect of severity of the residual stenosis of the infarctrelated coronary artery on left ventricular dilatation and function after acute myocardial infarction. J Am Coll Cardiol 1992;20:307-313.

17. Odemuyiwa O, Jordaan P, Malik M, farrell T, Staunton A, Poloniecki J, Ward D, Camm J. Autonomic correlates of late infarct artery patency after first myocardial infarction. Am Heart J 1993;125:1597-1600.

18. Meijer A, Verheugt FW, van Eenige MJ, Werter CJ. Left ventricular function at 3 months after successful thrombolysis. Impact of reocclusion without reinfarction on ejection fraction, regional function and remodelling. Circulation 1994;90:1706-1714.

19. Sambuceti G, Parodi O, Giorgetti A, Salvadori P, Marzilli M, Dabizzi P, Marzullo P, Neglia D, L'Abbate A. Microvascular dysfunction in collateral dependent myocardium. J Am Coll Cardiol 1995;26:615-623.

20. Gensini GG, Bruto da Costa BC. The coronary collateral circulation in living man. Am J Cardiol 1969;24:393-400.

21. Sabia PJ, Powers ER, Jayaweera AR, Ragosta M, Kaul S. Functional significance of collateral blood flow in patients with recent acute myocardial infarction. A study using myocardial contrast echocardiography. Circulation 1992;85:2080-2089. 